\title{
POLÍTICAS PÚBLICAS, BIBLIOTECAS ESCOLARES E O BIBLIOTECÁRIO NO CONTEXTO DA INDÚSTRIA 4.0
}

\section{PUBLIC POLICIES, SCHOOL LIBRARIES AND THE LIBRARIAN IN THE CONTEXT OF INDUSTRY 4.0}

\author{
Fabiana Salaa \\ Selma Leticia Capinzaiki Ottonicarb \\ Cláudio Marcondes de Castro Filhoc
}

\begin{abstract}
RESUMO
Introdução: A Indústria 4.0 ou 4ª Revolução Industrial vem sendo debatida na academia em áreas como a Engenharia e Administração. Essa nova revolução envolve a conexão dos objetos e sistemas ciber-físicos, criando as máquinas inteligentes. Essas tecnologias influenciam nos meios de produção e na vida das pessoas. Por isso, as bibliotecas são organizações que também precisam se adaptar à essas mudanças. Esse estudo é necessário para a Ciência da Informação porque demonstra a relevância da Indústria 4.0 para a área das bibliotecas e exige novo perfil do bibliotecário escolar 4.0. Objetivo: O objetivo do artigo envolve refletir a respeito do contexto da Indústria 4.0, políticas públicas brasileiras sobre Indústria 4.0 e seus impactos no papel e atuação do bibliotecário escolar 4.0. Metodologia: A metodologia é composta por uma revisão bibliográfica sobre Indústria 4.0, bibliotecas escolares, bibliotecário 4.0 e por uma pesquisa documental sobre as políticas públicas nesse contexto. Resultados: Os resultados demonstram que poucos artigos tratam da Indústria 4.0 na Ciência da Informação, por isso é oportunidade de pesquisa para a área. Além disso, os resultados apontam que o bibliotecário escolar 4.0 precisará modificar sua atuação para acompanhar essas mudanças. Conclusões: Como conclusões tem-se que as políticas públicas de Indústria 4.0 e a mudança das organizações exigem novos aprendizados do bibliotecário escolar 4.0, a fim de que a biblioteca escolar apoie os estudantes para que
\end{abstract}

a Doutoranda do Programa de Pós-Graduação em Ciência da Informação pela Universidade Estadual Paulista Júlio de Mesquita Filho (PPGCI-UNESP). Bibliotecária-Documentalista do Instituto Federal de Educação, Ciência e Tecnologia de São Paulo. E-mail: fabibuel@gmail.com.

b Doutoranda do Programa de Pós-Graduação em Ciência da Informação pela Universidade Estadual Paulista Júlio de Mesquita Filho (PPGCI-UNESP). E-mail: selma.leticia@hotmail.com.

c Livre-Docente em Políticas Públicas e Formação Profissional da Informação (2018). Pósdoutorado em Biblioteca Escolar na Universidade Aberta de Lisboa (2018). Doutorado em Ciência da Informação pela Universidade de São Paulo (2008). Mestrado em Ciência da Informação e Comunicação, pela Universidade de São Paulo (2002). Graduação em Comunicação Social pela Faculdade Anhembi Morumbi (1989) e em Biblioteconomia pela Fundação Escola de Sociologia e Política de São Paulo (1981). E-mail: claudiomarcondes54@gmail.com 
possam melhor se integrarem nesse contexto.

Descritores: Indústria 4.0. Políticas Públicas. Bibliotecas Escolares. Bibliotecário 4.0.

\section{INTRODUÇÃO}

A Indústria 4.0 ou 4ㄹ Revolução Industrial (14.0) vem sendo debatida na academia em áreas como a Engenharia e a Gestão Empresarial. Essa nova revolução envolve a conexão dos objetos e sistemas ciber-físicos (Cyber Physical Systems), criando as máquinas inteligentes (SCHWAB, 2016; ALAMADA-LOBO, 2015; DUTTON, 2014). Essas tecnologias influenciarão nos meios de produção e na vida das pessoas (SCHWAB, 2016).

O conceito de 14.0 surgiu a partir de 2011 em um evento da Hannover Messe na Alemanha. Por isso, esse país é um dos pioneiros e está investindo massivamente nessas tecnologias conectadas (RODRIGUES; JESUS; SCHÜTZER, 2016). A 14.0 conecta tecnologias como a inteligência artificial, impressão 3D, manufatura avançada ou fábricas inteligentes, informação nas nuvens, big data, internet das coisas (loT), entre outras tecnologias.

Esse contexto de 14.0 demanda que as bibliotecas escolares se adaptem para coexistir com as tecnologias conectadas e satisfazer os usuários. As escolas devem desenvolver currículos voltados à formação de pessoas capazes de lidar com a conexão dos objetos. Por isso, a parceria entre bibliotecários e professores é fundamental para o desenvolvimento do currículo. Para tanto, as bibliotecas escolares necessitam de tecnologias de informação e comunicação que possam elaborar ações em conjunto com alunos e professores, no sentido de não só ampliar conhecimento, mas também de melhorias no ensino e aprendizagem.

Cada vez mais as organizações exigirão pessoas capazes de analisar informação para construção de conhecimento, pois a tendência é a produção massiva de dados e informação. A prática de memorização já não será mais suficiente ao aprendizado, mas a análise da veracidade dos fatos e fontes de informação. Nesse sentido, o bibliotecário escolar 4.0 tem como foco a aprendizagem crítica e a busca do conhecimento ao longo da vida. 
As bibliotecas são organizações que devem se adaptar à essas mudanças. Portanto, esse estudo é necessário para a Ciência da Informação porque demonstra a relevância da 14.0 para a área das bibliotecas. Além disso, a 14.0 exige novo perfil do bibliotecário escolar 4.0 à medida que os usuários se familiarizam com as tecnologias inteligentes conectadas.

As pesquisas demonstram que, no Brasil, ainda são poucas as iniciativas e estudos que abordam as possibilidades de aplicação do conceito da Indústria 4.0 no âmbito da biblioteca escolar. Porém, a chegada de uma nova máxima e inovações tecnológicas é sempre uma oportunidade para que a biblioteca e o bibliotecário escolar 4.0 possam reinventar os serviços prestados à comunidade educacional, a fim de promover o acesso à informação de maneira mais eficaz e inteligente.

Assim, pautado nas demandas destacadas, a questão que norteia a problemática do estudo é: de que maneira a 14.0 e suas políticas públicas impactam nas bibliotecas escolares? O objetivo envolve refletir sobre os conceitos de 14.0, políticas públicas brasileiras sobre 14.0 e o papel do bibliotecário escolar 4.0 nesse contexto.

A pesquisa realizada tem caráter inovador à medida que traz conceitos utilizados pela área da tecnologia e gestão empresarial para o âmbito da biblioteca escolar. As transformações causadas pela 14.0, geram uma necessidade em se discutir o papel do bibliotecário escolar 4.0. Essa revolução tem modificado os modos de produção e a vida em sociedade, inclusive das bibliotecas escolares. A metodologia utilizada foi composta por uma revisão bibliográfica sobre 14.0, bibliotecas escolares, bibliotecário escolar 4.0 e por uma pesquisa documental sobre as políticas públicas brasileiras nesse contexto.

O artigo foi estruturado da seguinte maneira: o arcabouço teórico é composto pelos temas 14.0 e Bibliotecas Escolares e o Bibliotecário Escolar 4.0. Em seguida há uma breve descrição dos procedimentos metodológicos adotados para discutir esse conhecimento. As discussões discorrem sobre as teorias recentes das temáticas abordadas, das políticas públicas de 14.0 e do novo perfil bibliotecário. As considerações finais concluem os objetivos, respondem ao problema de pesquisa e aponta as limitações da pesquisa. 


\section{INDÚSTRIA 4.0}

A I4.0 é um assunto recente nas pesquisas acadêmicas de várias áreas como a Tecnologia de Informação (TI), Engenharia e Gestão Empresarial (GOEC; SANTOS; KORZENOWSKI, 2020; FRANK; DALENOGARE; AYALA, 2019). Esse tema apareceu nas discussões pela primeira vez em 2011 na Alemanha (HERMANN; PENTEK; OTTO, 2015) e, desde então, os países desenvolvidos e em desenvolvimento têm iniciado ações para ajudar as organizações a se adequarem a essas transformações.

A 14.0 é reconhecida como a 4a Revolução Industrial porque está mudando os modos de produção por meio da fábrica inteligente (KAGERMANN; WAHLSTER; HELBIG, 2013; HERMANN; PENTEK; OTTO, 2015; PEREIRA; SIMONETO, 2018; SCHWAB, 2016). Nessas fábricas, os objetos e sistemas conectados trocam informações e tomam pequenas decisões, a fim de melhorar o sistema produtivo (ALMADA-LOBO, 2015). Os produtos tendem a ser produzidos sob demanda, assim as empresas evitam o custo de armazenamento de produção (RODRIGUES; JESUS; SCHÜTZER, 2016).

Segundo o Programa 14.0 do Governo Federal (BRASIL, 2019, sem paginação):

As 3 primeiras revoluções industriais trouxeram a produção em massa, as linhas de montagem, a eletricidade e a tecnologia da informação, elevando a renda dos trabalhadores e fazendo da competição tecnológica o cerne do desenvolvimento econômico. A quarta revolução industrial, que terá um impacto mais profundo e exponencial, se caracteriza, por um conjunto de tecnologias que permitem a fusão do mundo físico, digital e biológico.

Há uma mudança nos modos de trabalho na medida em que algumas profissões se tornam obsoletas e novas funções emergem. Essas indústrias se utilizam da inteligência artificial, sistemas ciber-físicos, big data e loT para produzir a custo mais baixo com melhor qualidade, aumentando o lucro da empresa. Por isso, essas organizações demandam profissionais que saibam analisar e monitorar dados, em vez daqueles que realizavam atividades manuais e repetitivas.

Segundo Melo et al. (2018, p. 2061) a 14.0 é um conceito:

[...] proposto recentemente e que engloba as principais 
inovações tecnológicas dos campos de automação, controle e tecnologia da informação, aplicadas aos processos de manufatura. A partir de Sistemas Cyber-Físicos, Internet das Coisas e Internet dos Serviços, os processos de produção tendem a se tornar cada vez mais eficientes, autônomos e customizáveis.

A tendência é que as cidades se tornem também inteligentes por meio do uso dessas tecnologias da 14.0 (SAFIULLIN; KRASNYUK; KAPELYUK, 2019). Assim, os cidadãos têm mais tempo para lazer enquanto as máquinas realizam alguns trabalhos. A robotização é característica dessa revolução, pois há a prevalência de interação entre pessoas e máquinas (SCHWAB, 2016; ALMADALOBO, 2015). Atualmente, algumas empresas têm desenvolvido robôs de companhia que possuem um algoritmo programado segundo as preferências do cliente (FAST-BERGLUND; ÅKERMAN; SALUNKE, 2019).

Já foram criados robôs de companhia, limpadores de casa e outros capazes de produzir um produto na indústria inteligente. Os profissionais nas empresas poderão obter informação sobre a produção em tempo real (GHOURI; MANI, 2019). Há também o foco no desenvolvimento de carros autônomos, capazes de conduzir pessoas para qualquer lugar, drones para segurança e resgate, entre outros.

Nesse contexto, cientistas e filósofos têm ressaltado o papel da ética no desenvolvimento da inteligência artificial. A Europa criou um documento para criar empresas e institutos de pesquisa sobre os valores éticos na produção de robôs e outras tecnologias conectadas (MIAO, 2019; DARE, 2019; NATH; SAHU, 2020). É importante que as pessoas sejam críticas e saibam como discutir essas questões, pois os robôs poderão adquirir características preconceituosas presentes em seus criadores e refletir para a sociedade.

Ao mesmo tempo essas tecnologias são produtoras de informação e estão influenciando no sistema educacional, pois os métodos de ensino tradicionais já não suprem as necessidades de aprendizagem atuais. Algumas pesquisas têm ressaltado a importância da realidade virtual para simular situações reais. Com isso, o estudante pode exercitar aquele conhecimento na prática (STACHOVÁ et. al, 2019; ALMEIDA; SIMÕES, 2019).

Ressaltado que como equipamento cultural, e, portanto, também como 
produtora e de recursos de informação, as bibliotecas escolares têm papel central, principalmente porque propiciam o acesso e uso da informação. Essas bibliotecas contribuem com a aprendizagem dos estudantes desde a educação básica até os cursos universitários. Nesse contexto, as bibliotecas 4.0 aproveitam de tais tecnologias para organizar e disseminar a informação aos usuários (HUSSAIN, 2019). Por isso, aponta-se o papel do bibliotecário escolar 4.0 como facilitador do desenvolvimento da aprendizagem crítica.

\section{BIBLIOTECAS ESCOLARES E O BIBLIOTECÁRIO ESCOLAR 4.0}

As tecnologias sempre contribuíram com os avanços nas diversas áreas do conhecimento, mudando de forma vertiginosa os processos e otimizando os resultados. As mudanças tecnológicas do século XXI abrem novas possibilidades para a atuação do bibliotecário escolar 4.0., que perpassam desde as questões estruturais até o atendimento aos usuários.

Os desafios frente aos avanços tecnológicos estão inteiramente ligados à possibilidade de conversão de determinadas ações oriundas do contexto das bibliotecas para processos automatizados; sabe-se que a vantagem da tecnologia da informação é a sua capacidade de moldar-se à necessidade de um meio (SOUZA; CARVALHO, 2017, p. 1138).

As tecnologias tornam as bibliotecas mais atrativas e proporcionam um atendimento mais ágil para suprir as necessidades da sociedade. Semelhante ao que ocorre com as outras áreas da economia, o setor educacional e as bibliotecas escolares também passam pela 14.0. Diante desse cenário, as tecnologias inteligentes se destacam, pois suas características estão voltadas à capacitação na tomada de decisão e na obtenção de informações de maneira eficaz e rápida, proporcionando assim, mudanças expressivas no contexto informacional.

Nesse processo tecnológico evolutivo o papel do bibliotecário escolar 4.0 torna-se essencial, orientando e capacitando os usuários quanto à melhor forma de recuperação, acesso e uso de fontes de informação confiáveis. Nesse sentido, a biblioteca escolar 4.0 é um espaço criativo que estimula a inovação da comunidade educacional.

Diante das inúmeras possibilidades e fontes informacionais disponíveis, o 
trabalho do bibliotecário escolar 4.0 é visto como um forte aliado no combate a disseminação das fake news e distribuição deliberada de desinformação. "As mídias sociais contribuíram para a disseminação de informação de maneira mais ágil. A sociedade produz e consome informação concomitantemente. Os indivíduos precisam saber como interpretar a informação de maneira crítica" (OTTONICAR, et. al., 2019, p. 1).

Por meio de oficinas e atividades desenvolvidas na biblioteca, o bibliotecário escolar 4.0 ensina os alunos a pesquisarem na Internet, analisar a veracidade dos fatos e fontes de informação, visando a formação de estudantes críticos e aprendizes ao longo da vida. No contexto da biblioteca 4.0 os alunos aprendem sobre realidade aumentada, impressão $3 \mathrm{D}$ e se conectam com a biblioteca pela loT.

O papel do bibliotecário escolar 4.0 envolve não somente ensinar a pesquisar e filtrar informações, essa relação permite trabalhar a competência em informação, treinando os usuários no universo informacional disponível para que eles possam criar sua formação com suas próprias visões, dentro do seu campo e utilizando fontes confiáveis.

Diversos mecanismos complexos e eficientes foram desenvolvidos no decorrer dos anos. A finalidade de tais mecanismos é a de aumentar a eficiência na prospecção, localização, recuperação, utilização e divulgação das informações, função essa do bibliotecário escolar 4.0. Com usuários mais rigorosos e uma sociedade a um patamar de exigência além das fronteiras, as transformações digitais na biblioteca escolar contribuem para competências em informação do bibliotecário escolar 4.0.

As transformações digitais direcionam a sociedade a um patamar de exigência que sujeita a todos a pensarem além das fronteiras (NASCIMENTO, 2019). Já o conhecimento técnico deve estar atrelado às habilidades comportamentais. Criar, propor e se expor mais, fará toda a diferença na formação dos alunos. Esse preparo deve ser iniciado ainda no ensino básico, com a atuação da biblioteca escolar valorizando a descoberta e a pesquisa. A educação no contexto 4.0 prenuncia a (des) formatação e nos liberta de padrões que possam limitam o processo de criatividade (NASCIMENTO, 2019). 
Para tanto, o bibliotecário escolar 4.0 deve propor atividades que estimulem o debate, a fim de que os alunos possam aprender uns com os outros, além de se desafiarem a questionar e procurar novas alternativas e respostas. Neste contexto 4.0, entra em cena também a loT, uma proposta que conta com a capacidade de armazenamento em nuvem, o processamento e a análise de dados que faz uso de tecnologia móvel e sensores que podem ser instalados em dispositivos diversos que são capazes de captar informações e tratá-las de forma inteligente.

De acordo com Dutra e Toriani (2016), é possível ainda que, a loT utilize as informações de maneira tal que estas "coisas" interajam com total autonomia para a tomada de decisões, sem que seja necessário a presença humana.

No aspecto comercial a loT é uma realidade e cada vez mais tem conseguido maior espaço e é nessa contrapartida que é possível o seu desenvolvimento para ambientes domésticos, industriais, saúde e logística. As oportunidades da loT estão diretamente ligadas ao crescente número de dispositivos inteligentes e seu valor de negócio tem se tornado um atrativo para que novos investimentos surjam nessa área (SOUZA; CARVALHO, 2017, p. 1138).

A implantação da loT nas bibliotecas escolares torna-se oportuna, principalmente em relação ao serviço de atendimento à comunidade, uma vez que, permite a realização do tratamento da informação de forma mais dinâmica, por meio do uso de dispositivos inteligentes.

Dessa maneira, a biblioteca 4.0 deve estar voltada ainda para a prestação de serviços inovadores e a disponibilização de ambientes capazes de estimular a criatividade, também conhecidos como makerspaces.

Os makerspaces "são espaços de aprendizagem e criação que tem como característica desenvolver o pensamento crítico, explorar novas ideias, inventar, colaborar e que podem ser implementados inclusive em bibliotecas". (MOOREFIELD-LANG, 2015, p. 359, tradução nossa).

Entre as diversas possibilidades de equipamentos que podem ser disponibilizados nos makerspaces, as impressoras tridimensionais (3D), são as que possuem maior potencial de adesão para as bibliotecas, uma vez que o seu investimento inicial não demanda um alto investimento e o resultado de seu uso gera grande satisfação entre o público envolvido. 
Ao oferecer serviços e atividades que utilizem a impressora 3D as bibliotecas contarão com uma nova geração de usuários curiosos para saber como irá ficar determinado protótipo desenvolvido em softwares criados por eles próprios além de promover a livre expressão artística cada vez mais demandada pelos jovens (VIEIRA, 2017, p. 1114).

A utilização das impressoras 3D em bibliotecas estimula a criação de novos produtos que podem ser gerados com a utilização de softwares. Para isso, o papel da biblioteca em oferecer treinamento é essencial, pois capacita os usuários na busca por modelos pré-concebidos que são disponibilizados online.

Sobre o uso das impressoras 3D em bibliotecas, Wapner (2015) destaca que:

[...] a tecnologia de impressão em 3D está ajudando os estudantes a desenvolver habilidades voltadas para a ciência, tecnologia, engenharia, artes e matemática que os auxiliam a trabalhar num mercado competitivo onde as bibliotecas escolares, públicas, universitárias podem ajudar a liderar os esforços para promover este tipo de atividade em seu espaço.

Outra possibilidade de serviço que a Biblioteca 4.0 pode oferecer a seus usuários são os óculos inteligentes, um dispositivo em forma de óculos que possibilita a interação dos usuários com conteúdo em realidade aumentada.

Esses equipamentos podem gerar vários benefícios para a comunidade como fotografar a partir do comando de voz; gravar tutoriais e eventos que ocorrem na biblioteca; enviar mensagens instantâneas; reconhecimento óptico para pessoas com necessidades especiais; tradução simultânea, entre outras.

Contudo, as possibilidades de atuação da biblioteca escolar no contexto da 14.0 envolvem oferecer serviços cada vez mais integrados com as tecnologias e demandas dos usuários.

Isso ressalta o fato de que, mesmo com tantas mudanças e avanços tecnológicos a biblioteca continua sendo fundamental para o ensino, e que o advento tecnológico, seja ele em que nível for, só aumenta a importância e responsabilidade formativa desse equipamento informacional e do profissional que nele atua.

Entretanto, para que essas oportunidades sejam disponibilizadas e passem a fazer parte da rotina das bibliotecas escolares brasileiras, é necessário percorrer um longo caminho no embate por políticas públicas que reconheçam o 
papel formador das bibliotecas e invistam na sua promoção e modernização.

\section{METODOLOGIA}

A metodologia conta com a pesquisa bibliográfica (MARCONI; LAKATOS, 2013) que é considerada útil para temas inovadores. A 14.0 é um tema pouco discutido na área da Ciência da Informação (OTTONICAR; VALENTIM; MOSCONI, 2019). Portanto, esse tipo de pesquisa contribui com a conscientização e explicação sobre a temática para a área.

Realizou-se uma varredura no portal de Periódicos da Capes, Base de Dados Referenciais de Artigos de Periódicos em Ciência da Informação (BRAPCI), Google Scholar e Scientific Electronic Library Online (SciELO) sobre o tema da 14.0, bibliotecas escolares e bibliotecário 4.0. Entretanto, não foram encontrados artigos publicados, uma vez que, a relação entre políticas públicas, bibliotecas escolares e o bibliotecário escolar no contexto da indústria 4.0 ainda é uma temática recente e pouco abordada no Brasil.

No nível internacional, buscou-se artigos na Web of Science (WoS), Library Information Science Abstracts (LISA) e SCOPUS. Assim encontrou-se o artigo de Noh, Y., Imagining Library 4.0: Creating a Model for Future Libraries. The Journal of Academic Librarianship, v.41, n.6, p. 786-797, 2015.

Além disso, realizou-se pesquisa documental sobre as políticas públicas e ações governamentais brasileiras para apoiar as empresas e demais organizações a se adequarem ao contexto da 14.0. Essa pesquisa documental ocorreu em sites governamentais, em instituições de pesquisa como a Fundação de Amparo à Pesquisa do Estado de São Paulo (FAPESP), o Conselho Nacional de Desenvolvimento Cientifico e Tecnológico (CNPq) e a Coordenação de Aperfeiçoamento de Pessoal de Nível Superior (CAPES) e em organizações associadas à Indústria brasileira. A Figura 1 ilustra os procedimentos metodológicos. 


\section{Figura 1 - Procedimentos Metodológicos}

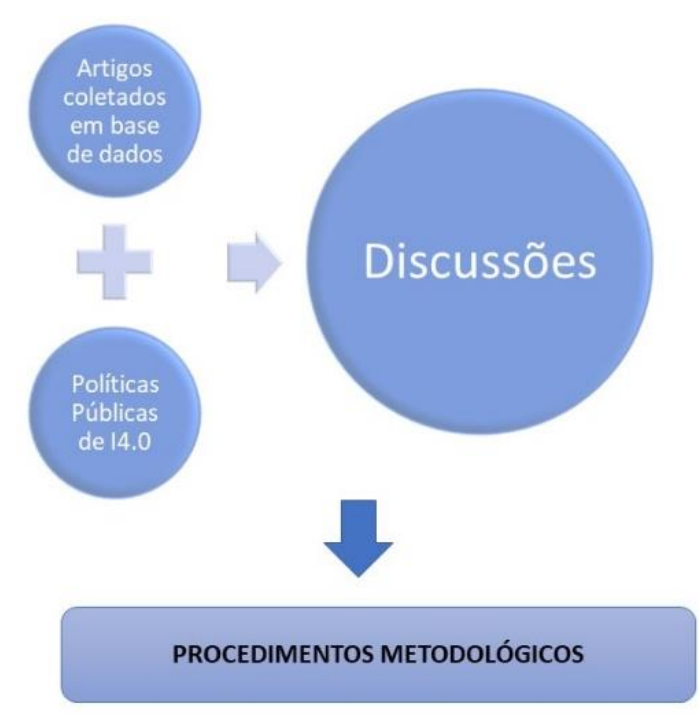

Fonte: Elaborado pelos autores (2020).

Os artigos coletados nas bases de dados e as políticas públicas no âmbito da 14.0 contribuem para a reflexão e as discussões. Diante da contextualização foi possível expor o papel do bibliotecário escolar 4.0 e como as transformações da 14.0 influenciam nas bibliotecas escolares.

\section{DISCUSSÕES}

A pesquisa documental possibilitou encontrar várias ações realizadas por organizações públicas e associações empresariais rumo à 14.0 no Brasil. Além disso, encontrou-se um artigo que trata dessa temática na área da Ciência da Informação no Brasil na BRAPCI.

O Brasil tem desenvolvido políticas públicas para ajudar as empresas a captar recursos e implementá-los em sua produção, seja no setor manufatureiro ou de serviços. Além disso, essas políticas têm como foco conscientizar os gestores de sua importância para o crescimento econômico do país e a lucratividade da empresa. Participam dessas políticas o Ministério das Comunicações, o Ministério da Ciência, Tecnologia, Inovação e Comunicações, - Ministério da Indústria, Comércio e Exterior e Serviços, a Confederação Nacional das Indústrias (CNI), o Serviço Nacional de Aprendizagem Industrial (SENAI), o Serviço Brasileiro de Apoio às Micro e Pequenas Empresas 
(SEBRAE), a Agência Brasileira de Desenvolvimento Industrial (ABDI), Ministério da Indústria, Comércio Exterior e Serviços (MDIC), a Associação Brasileira da Indústria de Máquinas e Equipamentos ( $A B I M A Q)$, Associação Catarinense de Empresas de Tecnologia (ACATE) e o Governo Federal.

O Brasil ainda não possui uma política pública específica para que as bibliotecas possam adotar tecnologias inteligentes e oferecer serviços diferenciados para os usuários. Parte destas políticas estão direcionadas às empresas que influenciam a educação e as bibliotecas, pois são organizações que apoiam a aprendizagem pela sociedade. Segundo Ottonicar, Valentim e Mosconi (2019) o Brasil está em momento de instabilidade política e crise econômica. Por isso, necessita fazer parcerias com outros países para melhorar a competitividade das empresas.

O Quadro 1 resume as principais políticas realizadas no Brasil voltadas a 14.0, conforme segue.

Quadro 1 - Principais ações e políticas públicas de 14.0 no Brasil

\begin{tabular}{|l|l|l|}
\hline Organizações & Ano & \multicolumn{1}{|c|}{ Ações, Políticas Públicas e Programas } \\
\hline $\begin{array}{l}\text { Ministério das } \\
\text { Comunicações }\end{array}$ & 2014 & $\begin{array}{l}\text { Plano Nacional de Comunicação M2M e Internet das } \\
\text { Coisas }\end{array}$ \\
\hline $\begin{array}{l}\text { Ministério da Ciência, } \\
\text { Tecnologia Inovação } \\
\text { e Comunicações }\end{array}$ & $2017 / 2018$ & $\begin{array}{l}\text { Estratégica Nacional de Ciência, Tecnologia e } \\
\text { Inovação (2016-2022)[1] } \\
\text { Plano de CT\&I para a manufatura avançada no Brasil } \\
\text { - ProFuturo: produção do futuro[2] } \\
\text { Plano de Ação de Ciência, tecnologia e Inovação em } \\
\text { Economia e Sociedade Digital - como eixo da } \\
\text { Estratégia Digital Brasileira[3]. } \\
\text { Plano Nacional de Internet das Coisas } \\
\text { Edital do Bônus Tecnológico } \\
\text { Prêmio Mercosul de Ciência e Tecnologia edição } \\
\text { 2018 - Tema Indústria 4.0[4] Formação da Rede } \\
\text { PD\&l de Manufatura Avançada no Agronegócio (em } \\
\text { formação) } \\
\text { Projeto Piloto de Extensão Tecnológica em } \\
\text { Manufatura Avançada - São Paulo } \\
\text { Seminário em Indústria Avançada no Brasil[5] }\end{array}$ \\
\hline
\end{tabular}




\begin{tabular}{|c|c|c|}
\hline $\begin{array}{l}\text { Inciativa conjunta } \\
\text { entre: } \\
\text { Ministério da } \\
\text { Indústria, Comércio e } \\
\text { Exterior e Serviços. } \\
\text { Ministério da Ciência, } \\
\text { Tecnologia, } \\
\text { Inovações } \\
\text { Comunicações }\end{array}$ & 2016 & $\begin{array}{l}\text { Perspectivas e Especialistas Brasileiros sobre } \\
\text { manufatura avançada no Brasil: um relato de } \\
\text { workshops realizados em sete capitais brasileiras em } \\
\text { contraste com as experiências internacionais.[6] }\end{array}$ \\
\hline $\begin{array}{l}\text { Confederação } \\
\text { Nacional das } \\
\text { Indústrias (CNI) }\end{array}$ & 2016 & $\begin{array}{l}\text { Programa Nacional para Elaboração e } \\
\text { Implementação de Plano Empresarial Estratégico de } \\
\text { Digitalização. } \\
\text { Elaboração do documento "Oportunidades para a } \\
\text { Indústria 4.0: aspectos da demanda e oferta no } \\
\text { Brasil". } \\
\text { Projeto Indústria } 2027\end{array}$ \\
\hline SENAI & & $\begin{array}{l}\text { MBI- Master Business in Innovation } \\
\text { Despertar } 4.0\end{array}$ \\
\hline $\begin{array}{l}\text { Agência Brasileira de } \\
\text { Desenvolvimento } \\
\text { Industrial (ABDI) }\end{array}$ & 2018 & $\begin{array}{l}\text { Agenda Brasileira para a Indústria } 4.0 \\
\text { Startup Indústria em parceria com MDIC (Programa } \\
\text { Nacional Conexão Startup-Indústria) }\end{array}$ \\
\hline ABIMAQ e ACATE & & Cluster Nacional para a Indústria 4.0 \\
\hline $\begin{array}{lr}\text { Ministério } & \text { da } \\
\text { Indústria, Comércio } \\
\text { Exterior e Serviços } \\
\text { (MDIC) }\end{array}$ & 2017 & $\begin{array}{l}\text { Criação de um grupo de trabalho para a } 14.0 \text { (GTI } \\
\text { 4.0). }\end{array}$ \\
\hline SEBRAE & & Aceleração Inovativa \\
\hline Governo Federal & & $\begin{array}{l}\text { Lei da Informática } \\
\text { Lei de Acesso à Informação } \\
\text { O Fundo Verde e Amarelo (FNDCT) } \\
\text { Fundo Nacional de Desenvolvimento Científico e } \\
\text { Tecnológico (FNDCT) }\end{array}$ \\
\hline
\end{tabular}

Fonte: Ottonicar, Valentim e Mosconi (2019, p. 566).

Essas políticas contribuem para que as organizações empresariais e as indústrias brasileiras possam buscar recursos e subsídios governamentais para se adequar à 14.0 no Brasil. Ressalta-se que o Brasil ainda carece de políticas públicas de bibliotecas 4.0 .

Segundo Rothmuller (2019) a 14.0 tem influenciado nos modos de 
aprendizagem, pois os novos alunos estarão adaptados a essas tecnologias conectadas, como a inteligência artificial por exemplo. Uma tendência é o uso da biblioteca digital, que permite o acesso à informação de forma remota por professores e alunos.

Os conteúdos de multimídia devem focar na qualidade, à medida que permitem maior abertura para personalização e variedade de conteúdo (ROTHMULLER, 2019). Esse assunto é bastante atual na área da Biblioteconomia e Ciência da Informação, assim é fundamental que mais pesquisas abordem o papel do bibliotecário escolar 4.0.

Essa revolução 4.0 é oportunidade para a utilização de tecnologias inteligentes visando o atendimento de um novo tipo de usuário, que anseia por serviços que ofereçam retorno cada vez mais rápido e participativo. Nesse contexto, há o aumento do ambiente de interação digital com menor custo (ZOOM, 2017; ROTHMULLER, 2019).

A área da Educação tem percebido os impactos da 14.0 nas formas de aprendizagem e, por isso, o Ministério da Educação (MEC) tem participado de eventos que discute quais as competências necessárias para os profissionais e cidadãos nesse contexto. Setores e profissões irão desaparecer e novos trabalhos irão surgir (BRASIL, 2019b).

Os profissionais estão se reinventando para mudar de profissão algumas vezes durante sua vida. Certas profissões estão desaparecendo e outras abrindo novas oportunidades. O foco é aprender ao longo da vida, valorizando a construção de conhecimento constante. As bibliotecas escolares 4.0 são fundamentais para o contexto da 14.0, pois influenciam na construção de um currículo voltado à pesquisa e ao pensamento crítico.

O foco da Educação 4.0 é a conexão entre pessoas, tecnologias e saberes. Há a valorização de projetos colaborativos com foco em metodologias ativas para estimular a criatividade em sala de aula (ANDRADE, 2019; FORESTI; VARVAKIS, 2019). Entretanto, ressalta-se que as ações voltadas à biblioteca 4.0 ainda são emergentes no Brasil.

Os estudantes estão se preparando para utilizar as tecnologias disruptivas em constante evolução. Todavia, não basta apenas saber utilizar as tecnologias, 
os alunos devem aprender como usar as informações de forma competente, para desenvolver e construir a criatividade. Segundo Andrade (2019), as pessoas devem saber tomar decisões inteligentes, ter liderança, respeitar as diferenças e trabalhar em equipe. Nesse sentido, o trabalho desenvolvido pelo bibliotecário escolar 4.0 na orientação ao uso de ferramentas de pesquisa contribui de forma significativa para a formação integral do cidadão que se almeja para a vida em sociedade e principalmente em instituições que busca pelo aprimoramento da utilização de tecnologias de ponta.

Segundo Foresti e Varvakis (2019), as bibliotecas escolares têm avançado rapidamente em direção ao universo digital, por isso, precisam competir com os dinâmicos buscadores comerciais. Nesse contexto, a criatividade é fundamental para que as bibliotecas escolares 4.0 se unam a esses buscadores e desenvolvam em seus usuários estratégias para o uso e compartilhamento de informações em escala global. "Portanto, ressalta-se a necessidades de políticas públicas e ações para guiar as bibliotecas escolares a se adequar à 14.0 e usufruir de suas tecnologias" (FOREST, VARVAKIS, 2019, p. 513).

Atento às demandas e transformações sociais, o Conselho Regional de Biblioteconomia do Estado de São Paulo - 8 ${ }^{\text {a }}$ Região (CRB8), promoveu em 2019, o VIII Encontro de Bibliotecários Educacionais, com foco nas bibliotecas do futuro conhecidas como Bibliotecas 4.01. Com o evento, o CRB8 deu início às discussões a respeito da necessidade de implementar as tecnologias disruptivas nas bibliotecas no Brasil.

De acordo com Hussain (2019), a educação 4.0 é interdisciplinar e centralizada na pesquisa e inovação. No contexto da 14.0 há uma valorização das características humanas como o amor, pois as máquinas estão cada vez mais inteligentes. Para Lee (2019), a diferença entre o ser humano e a máquina está nos sentimentos e essência.

Nessa mesma linha há a atuação da biblioteca 4.0 que está voltada aos aspectos humanos, assim: "[...] é uma transformação de mão dupla que muda o

\footnotetext{
${ }^{1}$ Disponível em: http://www.crb8.org.br/o-novo-conceito-sobre-as-bibliotecas-4-0/. Acesso em 07 jun. 2020.
} 
fato de conhecer a coleção da biblioteca para conhecer a sua conexão" (HUSSAIN, 2019, p. 1, tradução nossa). Nesse sentido, ressalta-se que, a parceria entre bibliotecário e professores possibilita o desenvolvimento de um currículo efetivo para que os alunos desenvolvam competências informacionais essenciais no uso das tecnologias da 14.0.

Noh (2015); Labangon e Manabat (2019), apontam que a biblioteca 4.0 implica em novos conceitos que modificam os processos como biblioteca inteligente (intelligent library), biblioteca com dados massivos (massive data library), biblioteca de realidade aumentada (augmented reality library), biblioteca baseada em contexto (context-aware library), biblioteca de ponta (cutting-edge recognition library) e espaço criativo infinito (infinite creative space). O quadro 2 resume tais conceitos.

\section{Quadro 2 - Conceitos que implicam na biblioteca 4.0}

\begin{tabular}{|l|l|}
\hline \multicolumn{1}{|c|}{ Termo } & \multicolumn{1}{|c|}{ Conceitos } \\
\hline Biblioteca inteligente & $\begin{array}{l}\text { Biblioteca equipada com tecnologias conectadas por meio } \\
\text { da loT e de tecnologias de inteligência artificial que antecipa } \\
\text { as necessidades dos usuários. Essa biblioteca engloba os } \\
\text { demais conceitos que podem aparecer no contexto da I4.0. }\end{array}$ \\
\hline $\begin{array}{l}\text { Biblioteca com dados } \\
\text { massivos }\end{array}$ & $\begin{array}{l}\text { Biblioteca que coleta dados sobre os usuários em tempo } \\
\text { real por meio de aplicativos de celular, dados de navegação } \\
\text { de tablets, computadores e equipamentos inteligentes. }\end{array}$ \\
\hline $\begin{array}{l}\text { Biblioteca de realidade } \\
\text { virtual }\end{array}$ & $\begin{array}{l}\text { A biblioteca de realidade pode estar presente tanto espaço } \\
\text { físico quanto virtual. Escolher os livros e participar de } \\
\text { atividades disponíveis. Além disso, podem usufruir dos } \\
\text { vários serviços de maneira digital e suprir suas dúvidas de } \\
\text { maneira remota. }\end{array}$ \\
\hline $\begin{array}{l}\text { Biblioteca de realidade } \\
\text { aumentada }\end{array}$ & $\begin{array}{l}\text { Os usuários utilizam os óculos de realidade aumentada para } \\
\text { visitar a biblioteca. Assim participam de cursos, escolhem } \\
\text { livros, aprendem por meio dos jogos de realidade virtual. A } \\
\text { realidade aumentada propicia a aplicação do conhecimento } \\
\text { por meio da prática. }\end{array}$ \\
\hline $\begin{array}{l}\text { Biblioteca baseada em } \\
\text { contexto }\end{array}$ & $\begin{array}{l}\text { Biblioteca especializada focada em um grupo ou } \\
\text { comunidade. Essa biblioteca também engloba as } \\
\text { tecnologias inteligentes adaptadas aos usuários. Essa } \\
\text { biblioteca oferece serviços diferenciados e específicos. }\end{array}$ \\
\hline Biblioteca de ponta & $\begin{array}{l}\text { Biblioteca que se utiliza de alta tecnologia como impressão } \\
\text { 3D, loT, Big Data, Robôs. Essas bibliotecas também podem } \\
\text { estar presentes em institutos de pesquisa. }\end{array}$ \\
\hline Espaço criativo infinito \\
$\begin{array}{l}\text { Biblioteca ou museu com foco na criatividade e inovação } \\
\text { dos usuários. }\end{array}$ \\
\hline Fonaptado de Noh (2015), Labangon e Manabat (2019).
\end{tabular}

Fonte: Adaptado de Noh (2015), Labangon e Manabat (2019). 
Os conceitos de biblioteca que aparecem no contexto da 14.0 não são excludentes, mas se complementam. Independente do termo adotado, a biblioteca 4.0 necessita, em um primeiro momento, adotar as tecnologias disruptivas para em seguida, inovar e oferecer um serviço de qualidade. Essas bibliotecas podem convergir entre o espaço físico e o digital, automatizando processos.

Nesse sentido, na área de ensino e aprendizagem, as metodologias ativas de aprendizagem emergem nesse contexto de tecnologias inteligentes, porque são meios de ensino diversificados. Essas metodologias formam indivíduos que se adaptam, aprendem de modo interdisciplinar, colaboram e se tornam autônomos. A Base Nacional Comum Curricular (BNCC) aponta as competências essenciais a serem desenvolvidas na educação básica, conforme a figura 2.

Figura 2 - Base Nacional Comum Curricular e Competências

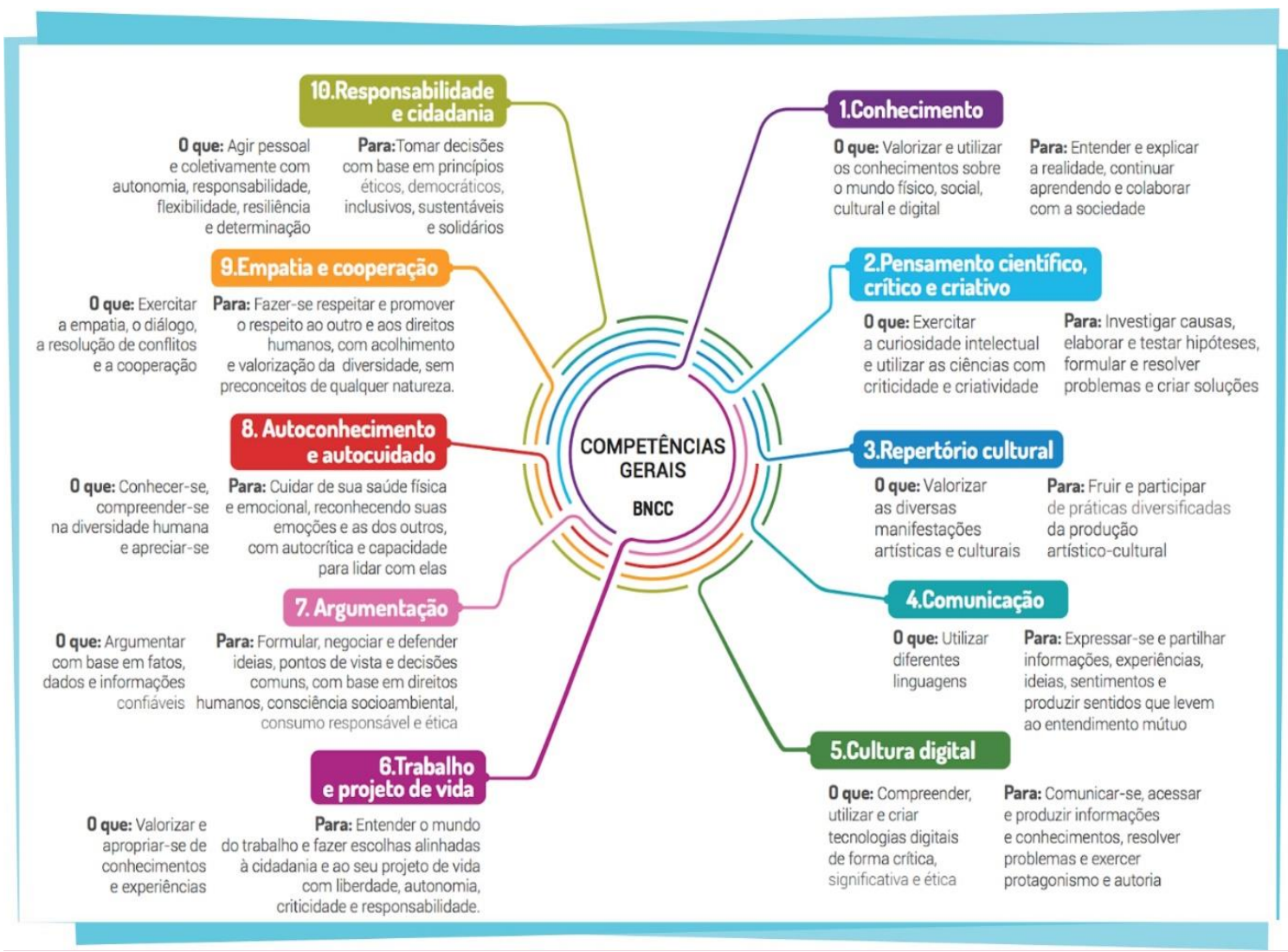

Fonte: Brasil (2013).

A BNCC norteia as competências a serem desenvolvidas, principalmente no contexto das tecnologias digitais. Assim, essas competências são o foco das 
bibliotecas escolares 4.0 para que seus programas e serviços se adequem à:

1) Tecnologias conectadas como inteligência artificial voltado à aprendizagem personalizada;

2) Valorização de conhecimentos por meio do aprender a aprender durante a vida;

3) Desenvolvimento de atividades com foco no pensamento crítico, por isso, é importante a inserção da competência em informação;

4) Valorizar as diferentes manifestações artísticas produzidas pelo ser humano e também pelos algoritmos;

5) Comunicação eficaz com o público e incentivar a aprendizagem de outros idiomas, respeitando imigrantes e sua cultura;

6) Possuir cultura digital de atualização constante e estabelecer espaços de discussão sobre as consequências da 14.0 para a sociedade;

7) Estimular a empatia e a cooperação entre as pessoas e as tecnologias;

8) Desenvolver a autonomia dos usuários para aprender ao longo da vida;

9) Responsabilidade social e cidadania com foco na sustentabilidade do país.

A biblioteca escolar é fundamental para a educação, principalmente no contexto desafiador da 14.0. A missão da biblioteca escolar 4.0 é formar os alunos quanto a recuperação e utilização das informações de maneira crítica. Os estudantes devem ser capazes de aprender de maneira autônoma por meio de fontes confiáveis de informação. Hussain (2019), aponta que a 14.0 é um desafio para que os profissionais bibliotecários mantenham seu emprego no futuro. Desse modo, os bibliotecários escolares 4.0 devem caminhar na direção dessa nova revolução, utilizando a inteligência artificial e demais tecnologias a seu favor.

O bibliotecário escolar 4.0 tem como responsabilidade fornecer educação de qualidade e justa voltada à inclusão escolar e participação digital. Conforme explica Castro Filho $(2018$, p. 8) este profissional desenvolve: "[...] ação pedagógica, de incentivo e de práticas à leitura, com inserção de atividades lúdicas complementares ao processo tradicional de ensino-aprendizagem". Além disso, o bibliotecário escolar 4.0 é fundamental no processo de criação e 
efetivação de políticas públicas educacionais e culturais da 14.0.

O bibliotecário escolar 4.0 compreende que "as mudanças induzidas pelas tecnologias da comunicação (sobretudo celulares e iPads) continuarão a provocar um 'terremoto positivo' na vida das pessoas, assim como um aumento na oferta de cultura e uma diversificação de alternativas" (MASI, 2015, p. 304). Assim propõe produtos e serviços na biblioteca escolar com as tecnologias inteligentes conectadas.

Hjerpe (2016, tradução nossa) salienta em estudo realizado que no ano de 2045, as bibliotecas terão como assistentes robôs que ajudariam estudantes e pesquisadores a acessar o material arquivado, e que grande parte das instalações da biblioteca seria usada para ensino e pesquisa.

Diante das frequentes modificações e flexibilização no contexto social e de trabalho, há a necessidade de desenvolver o aprendizado ao longo da vida, além da sala de aula. Nesse sentido a biblioteca escolar e o bibliotecário escolar 4.0 tem muito a colaborar pois, promovem a pesquisa, a troca de ideias e experiências como base do conhecimento. Competências que são cobradas além dos muros da escola.

\section{CONSIDERAÇÕES FINAIS}

O desenvolvimento das bibliotecas escolares está diretamente ligado ao avanço tecnológico. Por isso, faz-se necessário iniciar as discussões no âmbito da biblioteca 4.0, uma vez que esse conceito começa a tomar forma na realidade e criar novas possibilidades de atuação para o bibliotecário escolar 4.0. Nesse contexto, a biblioteca 4.0 está atrelada aos conceitos de tecnologias disruptivas ou inteligentes, makerspace, loT, realidade aumentada, serviço cloud e bibliotecário escolar 4.0.

Diante dos desafios da 14.0, a biblioteca escolar, enquanto unidade de educação, social e cultura, tem apresentado grandes possibilidades de utilização dessas tecnologias aprimorando a qualidade dos produtos e serviços ofertados à comunidade educacional. No entanto, é necessário reconhecer que ainda há um longo caminho a ser percorrido, principalmente no âmbito da formulação e implementação de políticas públicas voltadas para o investimento e valorização 
das bibliotecas no país, visto que, são inúmeras as possibilidades para a aplicação do conceito da 14.0 nas bibliotecas escolares brasileiras.

Por fim, considera-se que a pesquisa é limitada por considerar apenas as políticas públicas brasileiras. Há um vasto campo de pesquisa no assunto que pode ser otimizado por futuras pesquisas na área de Biblioteconomia e Ciência da Informação. Como sugestão a pesquisas futuras tem-se de realizar a aplicação de padrões e indicadores de competência em informação para que as bibliotecas valorizem o conhecimento crítico e contribuam na formação dos indivíduos, principalmente nas bibliotecas de cursos de formação industrial.

\section{REFERÊNCIAS}

ALMADA-LOBO, F. The industry 4.0 revolution and the future of Manufacturing Execution Systems (MES). Journal of Innovation Management, v. 3, n. 4, p. 16-21, 2015. Disponível em:

https://www.researchgate.net/publication/306150248_The_Industry_40_revoluti on_and_the_future_of_Manufacturing_Execution_Systems_MES. Acesso em: 09 jun. 2020.

ALMEIDA, F.; SIMOES, J. The Role of Serious Games, Gamification and Industry 4.0 Tools in the Education 4.0 Paradigm. Contemporary Educational Technology, v. 10, n. 2, p. 120-136, 2019.

Disponível em: https://www.cedtech.net/article/the-role-of-serious-gamesgamification-and-industry-40-tools-in-the-education-40-paradigm-6239. Acesso em: 09 jun. 2020.

ANDRADE, K. Guia definitivo da educação 4.0: Uma rede de conexões interligando pessoas e saberes. Disponível em:

http://www.plannetaeducacao.com.br/portal/arquivo/editor/file/ebookeducacao4.0-planneta.pdf. Acesso em: 13 set. 2019.

BRASIL. Ministério da Educação. Base Nacional Comum Curricular: educação é a base. Brasília: Ministério da Educação, [2013]. Disponível em: http://basenacionalcomum.mec.gov.br/images/BNCC_EI_EF_110518_versaofin al_site.pdf. Acesso em: 13 set. 2019.

BRASIL. Ministério da Educação. MEC participa de evento que discute o impacto da educação na economia do país. Brasília: Ministério da Educação, 2019b. Disponível em:

http://portal.mec.gov.br/component/tags/tag/50121. Acesso em: 13 set. 2019. BRASIL. Ministério da Indústria, Comércio e Serviços. Agenda brasileira para a indústria 4.0: o Brasil preparado para os desafios do futuro. Brasília: 
Ministério da Indústria, 2019. Disponível em: http://www.industria40.gov.br/. Acesso em 21 maio 2019.

CASTRO FILHO, C. M. Agenda 2030 para o desenvolvimento sustentável: uma leitura de política pública na clave da biblioteca escolar. RDBCI: Revista Digital de Biblioteconomia e Ciência da Informação, Campinas, v. 16, n. 3, p. 355-372, 2018. Disponível em: https://periodicos.sbu.unicamp.br/ojs/index.php/rdbci/article/view/8650931. Acesso em: 09 jun. 2020.

DARE, T. Ethics of artificial intelligence and health care. The New Zealand Medical Student Journal, n. 128, 2019. Disponível em:

http://www.nzmsj.com/uploads/3/1/8/4/31845897/7_28nzmsj-28-completeonline.pdf. Acesso em: 09 jun. 2020.

DUTRA, M. L.; TORIANI, S. A. Internet das coisas na prática: desafios e oportunidades. In: PRADO, J. D. (Org.). Ideias emergentes em Biblioteconomia. São Paulo: FEBAB, 2016. p. 86-92. Disponível em: www.ideiasemergentes.wordpress.com. Acesso em: 07 jul. 2019.

DUTTON, W. H. Putting things to work: social and policy challenges for the Internet of things. Info, v. 16, n. 3, p. 1-21, 2014. Disponível em: https://www.researchgate.net/publication/275373213_Putting_things_to_work Social_and_policy_challenges_for_the_Internet_of_things. Acesso em: 09 jun. 2020.

FAST-BERGLUND, A.; ÅKERMAN, M; SALUNKE, D. L. O. Conceptualising Assembly 4.0 through the drone factory. IFAC-PapersOnLine, v. 52, n. 13, p. 1525-1530, 2019. Disponível em: https://www.sciencedirect.com/science/article/pii/S2405896319313977. Acesso em: 04 jun. 2020.

FORESTI, F.; VARVAKIS, G. A biblioteca e o novo paradigma produtivo da indústria 4.0. Revista ACB, Florianópolis, v. 24, n. 3, p. 513-535, dez. 2019. Disponível em: https://revista.acbsc.org.br/racb/article/view/1527. Acesso em: 04 jun. 2020.

FRANK, A.G.; DALENOGARE, L.S.; AYALA, N.F. Industry 4.0 technologies: implementation patterns in manufacturing companies. Int. J. Prod. Econ., v. 210, p. 15-26, 2019. Disponível em: https://www.sciencedirect.com/science/article/abs/pii/S0925527319300040. Acesso em: 04 jun. 2020.

GHOURI, A. M.; MANI, V. Role of real-time information-sharing through SaaS: an industry 4.0 perspective. International Journal of Information Management, v. 49, p. 301-315. Disponível em: https://www.sciencedirect.com/science/article/abs/pii/S0268401218312799. Acesso em: 04 jun. 2020. 
GOEC, L. S.; SANTOS, A. A.; KORZENOWSKI, A. L. Decision-making trends in quality management: a literature review about Industry 4.0. Prod., São Paulo, v. 30, 2020. Disponível em: https://www.scielo.br/scielo.php?pid=S010365132020000100704\&script=sci_arttext. Acesso em: 04 jun. 2020.

HERMANN, M.; PENTEK, T.; OTTO, B. Design Principles for Industrie 4.0 Scenarios: a literature review. Working Paper, Technische Universität, Dortmund, Austria, 2015. Disponível em:

https://www.researchgate.net/publication/307864150_Design_Principles_for_In dustrie_40_Scenarios_A_Literature_Review. Acesso em: 9 jun. 2020.

HJERP, Anika. Robots, holograms and libraries. Scandinavian Library Quately. Stockholm, Suécia, v. 49, n. 4. 2016. Disponível em: http://slq.nu/index4e5d.html?article=volume-49-no-4-2016-12. Acesso em: 9 jun. 2020.

HUSSAIN, A. Industrial revolution 4.0: implication to libraries and librarians, Library Hi Tech News, v. 37, n. 1, 2019, p. 1-5. Disponível em: https://www.researchgate.net/publication/336157559_Industrial_revolution_40_i mplication_to_libraries_and_librarians. Acesso em: 9 jun. 2020.

KAGERMANN, H.; WAHLSTER, W.; J. HELBIG, J. Recommendations for implementing the strategic initiative Industrie 4.0: final report of the Industrie 4.0 Working Group, 2013. Disponível em:

https://www.din.de/blob/76902/e8cac883f42bf28536e7e8165993f1fd/recommen dations-for-implementing-industry-4-0-data.pdf. Acesso em: 9 jun. 2020.

LABANGON, D. L.; MANABAT, A. Establishing Connections, Bridging the Gap: Library 4.0 and Its Role in Digital Humanities. In: DLSU RESEARCH CONGRESS, Manila, Philippines: De La Salle University, 2019. Disponível em: https://www.dlsu.edu.ph/wp-content/uploads/pdf/conferences/researchcongress-proceedings/2019/lli-II-015.pdf. Acesso em: 10 jun. 2020.

LEE, K. F. Inteligência Artificial: como os robôs estão mudando o mundo, a forma como amamos, nos relacionamos, trabalhamos e vivemos. Rio de Janeiro: Globo Livros, 2019.

MARCONI, M. A; LAKATOS, E. M. Técnicas de pesquisa: planejamento e execução de pesquisas, amostragens e técnicas de pesquisa, elaboração, análise e interpretação de dados. 7. ed. São Paulo: Atlas, 2013.

MASI, D. Caminhos da cultura no Brasil. Rio de Janeiro: Sextante, 2015.

MELO, M. R; LIMA, P. R. de; PIRES, V. A; HOLANDA, J. P; WOBETO, R; QUEIROZ, A. L. Indústria 4.0: inovando com qualidade. In: CONGRESSO INTERNACIONAL DE PESQUISA, ENSINO E EXTENSÃO, 3., 2018. Anais 
[...]. [s.l.]: UniEvangélica, 2018. Disponível em: http://anais.unievangelica.edu.br/index.php/CIPEEX/article/view/2177/1661. Acesso em: 05 jun. 2020.

MIAO, Z. Investigation on human rights ethics in artificial intelligence researches with library literature analysis method, The Electronic Library, v. 37 n. 5, 2019, p. 914-926. Disponível em:

https://www.researchgate.net/publication/336802191_Investigation_on_human rights_ethics_in_artificial_intelligence_researches_with_library_literature_analy sis_method. Acesso em: 09 jun. 2020.

MOOREFIELD-LANG, $\mathrm{H}$. User agreements and makerspaces: a content analysis. New Library World, v. 116, n. 7/8, p. 358-368, 2015. Disponível em: https://pdfs.semanticscholar.org/2a2c/3d25235ec1ed39bbef98d4b8d61164ed6a 94.pdf?_ga=2.142123444.740451087.1591713384-1046156365.1591713384. Acesso em: 09 de jun. 2020.

NASCIMENTO, A. Educação e tecnologia superarão os limites. Disponível em: https://itforum365.com.br/educacao-e-tecnologia-superarao-os-limites/. Acesso em: 25 de mar. 2019.

NATH, R., SAHU, V. The problem of machine ethics in artificial intelligence. Al \& Soc. v. 35, 2020, p. 103-111. Disponível em: https://www.researchgate.net/publication/320507254_The_problem_of_machin e_ethics_in_artificial_intelligence. Acesso em: 09 jun. 2020.

$\mathrm{NOH}, \mathrm{Y}$. Imagining Library 4.0: Creating a Model for Future Libraries. The Journal of Academic Librarianship, v. 41, n. 6, p. 786-797, 2015. Disponível em: https://www.sciencedirect.com/science/article/abs/pii/S0099133315001780. Acesso em: 10 jun. 2020.

OTTONICAR, S. L. C; VALENTIM, M. L. P; JORGE, L. F; MOSCONI, E. Fake news, big data e o risco à democracia: novos desafios à competência em informação e midiática. In: ENCONTRO IBÉRICO, 9., 2019, Anais [...]. Barcelona. Disponível em: https://www.semanticscholar.org/paper/Fakenews\%2C-big-data-e-o-risco-\%C3\%A0-democracia\%3A-novos-\%C3\%A0Ottonicar-Valentim/d6f3d6f5ab59df317647d00f48a8bc258c49e1c4. Acesso em: 25 mar. 2019.

OTTONICAR, S; VALENTIM, M.; MOSCONI, E. Políticas públicas aplicadas à indústria 4.0: estudo comparativo entre o Brasil e o Canadá com foco na competência em informação. Revista Ibero-Americana de Ciência da Informação, v. 12, n. 2, 2019, p. 558-584. Disponível em: https://periodicos.unb.br/index.php/RICl/article/view/19596. Acesso em: 07 jun. 2020.

PEREIRA, A.; SIMONETTO, E. de O. Indústria 4.0: conceitos e perspectivas para o Brasil. Revista da Universidade Vale do Rio Verde, v. 16, n. 1, jan./jul. 
2018. Disponível em:

http://periodicos.unincor.br/index.php/revistaunincor/article/view/4938. Acesso em: 07 jun. 2020.

RODRIGUES, L. F.; JESUS, R. A.; SCHÜTZER, K. Industrie 4.0: uma revisão da literatura. Revista de Ciência \& Tecnologia, Piracicaba, p. 1-13, 2016. Disponível em: https://www.metodista.br/revistas/revistasunimep/index.php/cienciatecnologia/article/view/3176. Acesso em: 07 jun. 2020.

ROTHMULLER, C. 5 razões para investir na biblioteca 4.0. Disponível em: http://www.crb8.org.br/5-razoes-para-investir-na-biblioteca-4-0/. Acesso em: 13 set. 2019.

SAFIULLIN, A.; KRASNYUK, L.; KAPELYUK, Z. Integration of Industry 4.0 technologies for "smart cities" development. In: IOP Conference Series: Materials Science and Engineering, 497., 2019, Saint-Petersburg. Anais [...] Saint-Petersburg: International Scientific Conference "Digital Transformation on Manufacturing, Infrastructure and Service" Saint-Petersburg, Russian Federation, 2019. Disponível em: https://iopscience.iop.org/article/10.1088/1757-899X/497/1/012089/meta. Acesso em: 04 jun. 2020.

SCHWAB, K. The fourth industrial revolution. New York: Crown Business, 2016.

SOUZA, T. L.; CARVALHO, T. Internet das coisas (IoT) em bibliotecas universitárias brasileiras: diagnóstico situacional. RBBD Revista Brasileira de Biblioteconomia e Documentação, São Paulo, v. 13, p. 1136-1147, dez. 2017. Disponível em: https://rbbd.febab.org.br/rbbd/article/view/902. Acesso em: 28 jul. 2019.

STACHOVÁ, K.; PAPULA, J.; STACHO, Z.; KOHNOVÁ, L. External Partnerships in Employee Education and Development as the Key to Facing Industry 4.0 Challenges. Sustainability, v. 11, 2019. Disponível em: https://www.mdpi.com/2071-1050/11/2/345\#cite. Acesso em: 04 jan. 2020.

VIEIRA, D. V. Inovação em bibliotecas: considerações sobre a disponibilização de serviço de impressão 3D. In: CONGRESSO BRASILEIRO DE BIBLIOTECONOMIA E DOCUMENTAÇÃO, 27., 2017. Anais [...]. Fortaleza: FEBAB, 2017. p. 1825-1830. Disponível em: https://rbbd.febab.org.br/rbbd/article/view/875. Acesso em: 28 jul. 2019.

WAPNER, C. Progress in the making: 3d printing policy considerations through the library lens. OITP Perspectives, n. 3, p. 1-21, 2015. Disponível em:

http://www.ala.org/advocacy/sites/ala.org.advocacy/files/content/advleg/pp/pu b/perspectives-3D_Library_Policy-ALA_OITP_Perspectives-2015Jan06.pdf. Acesso em: 28 jul. 2019. 
ZOOM comunicação. Biblioteca na revolução 4.0: desafio ou oportunidade?

Praxis Softwares Gerenciais, Belo Horizonte, 07 de fev. 2019. Disponível em: https://praxis.com.br/biblioteca-na-industria-4-0-desafio-ou-

oportunidade/\#: :text=A\%20quarta\%20revolu\%C3\%A7\%C3\%A30\%20industrial \%20define,intera\%C3\%A7\%C3\%A30\%20entre\%20pessoas\%20e\%20tecnologi as.\&text $=$ Os\%20acervos\%20on\%2Dline \%20ganharam,conversas $\% 20 \mathrm{e} \% 20$ troc a\%20de\%20conhecimento. Acesso em: 13 set. 2019.

\title{
PUBLIC POLICIES, SCHOOL LIBRARIES AND THE LIBRARIAN IN THE CONTEXT OF INDUSTRY 4.0
}

\begin{abstract}
Introduction: Industry 4.0 or 4nd Industrial Revolution is being debated in academia in various areas such as Engineering and Business Administration. This new revolution involves the connection of objects and cyber-físicos systems, creating intelligent machines. These technologies will influence in the means of production and the lives of people. Therefore, the libraries are organizations that also need to adapt to these changes. This study is necessary for the Information Science because it demonstrates the relevance of Industry 4.0 for the area of libraries and requires new profile of the school librarian. Objective: The objective of the article involves reflect the concerns of the industry context 4.0, Brazilian public policies on industry 4.0 and its impacts on the role and activities of the school librarian. Methodology: The methodology is composed by a bibliographic review on Industry 4.0, school libraries, Librarian 4.0 and a documentary research on public policies in this context. Results: The results show that few articles deal with the Industry 4.0 in Information Science, why is the opportunity to search for the area. In addition, the results suggest that the librarian will need to modify its performance to keep pace with these changes. Conclusions: As conclusions has been that public policies for Industry 4.0 and the change of organizations will require new learnings of the librarian, in order that the school library support students to fit in this context.
\end{abstract}

Descriptors: Industry 4.0. Public policy. Media centers. Librarian 4.0.

\section{POLÍTICAS PÚBLICAS, BIBLIOTECAS ESCOLARES Y EL PROFISSIONAL DE LA INFORMACIÓN EN EL CONTEXTO DE LA INDUSTRIA 4.0}

\begin{abstract}
RESUMEN
Introducción: La industria 4.0 o $4^{\text {a }}$ Revolución Industrial está siendo debatido en la academia en diversos ámbitos tales como la ingeniería y la administración de empresas. Esta nueva revolución implica la conexión de objetos y sistemas ciber-físicos, creando máquinas inteligentes. Estas tecnologías tendrán influencia en los medios de producción y la vida de las personas. Por lo tanto, las bibliotecas son organizaciones que también deben adaptarse a esos câmbios. Este estudio es necesario para la ciencia de la información, porque demuestra la importancia de la Industria 4.0 para el área de
\end{abstract}

Inf. Inf., Londrina, v. 25, n. 2, p. $430-455$, abr./jun. 2020. 
bibliotecas y exige un nuevo perfil del bibliotecario escolar. Objetivo: El objetivo del artículo consiste en reflejar las preocupaciones de la industria contexto 4.0, políticas públicas brasileñas de industria 4.0 y sus impactos sobre el papel y las actividades del bibliotecario escolar. Metodología: La metodología está compuesta por una revisión bibliográfica sobre la Industria 4.0, las bibliotecas escolares, Bibliotecario 4.0 y una investigación documental sobre políticas públicas en este contexto. Resultados: Los resultados muestran que pocos artículos se relacionan con la industria 4.0 en Ciencias de la información, ¿por qué es la oportunidad para buscar la zona. Además, los resultados sugieren que el bibliotecario tendrá que modificar su rendimiento para seguir el ritmo de estos cambios. Conclusiones: Como conclusiones, ha sido que las políticas públicas para la Industria 4.0 y el cambio de las organizaciones necesitarán nuevos aprendizajes del bibliotecario, a fin de que la biblioteca de la escuela de apoyo para los alumnos que encajan en este contexto.

Descriptores: Industria 4.0. Políticas Públicas. Bibliotecas Escolares. Bibliotecario 4.0.

Recebido em: 22/10/2019

Aceito em: 03/06/2020 